downward direction, and more to the left than to the right. When the right auricle is dilated there is usually engorge. inent of the veins of the neck and other signs of cardiac fatilure.

To map out accurately on the chest wall the right border of the heart is difficult, if not impossible, even in the hiands of experts. It is better to rely on signs of venous engorgement, which all can recognize as indicating ditatation of the right auricle. It is certainly wrong to consider iucrease in the size of the heart to the right as a sign of oulargement of the right ventricle. Epigastric pulsation is too inconstant in mitral stenosis, and too frequently observed in patients with normal hearts to be of service as a sign of right ventricular hypertrophy. It is generally safe when there is a sign of enlargement of the heart to the left to consider the whole heart as increased in size. It is true that in mitral stenosis the hypertrophy which medominates is usually a right ventricular one, but it is equally true that both ventricles are usually hypertrophied. (1)servations which Lewis and I made have shown this. We weighed separately the ventricles of a large number of hearts with mitral stenosis, and found the hypertrophy to be general, but with a relative increase in the weight of the right ventricle. Such pathological findings, together with electro-cardiographio records, do not support the hypothesis that the valvular defect is the only factor in the production of hypertrophy in mitral stenosis. Some other cause must be found to explain the increase in weight of the muscle in both ventricles.

Prognosis is difficult in early mitral stenosis. By the symptoms alone as I have described them one may gauge the man's present capacity for work. The exercise tolerance, as determined by a simple exercise test, gives useful information concerning his present disability. As a measure of physical endurance the reaction to exercise is of prognostic value. As a test to be employed in predicting the duiation of life it is not to be relied upon. Good exercise tolerance is never observed when there are signs of heart failure. Poor exercise tolerance is not necessarily issociated with a cardiac breakdown. It is true that there ire symptoms which so incapacitate that total disability is at once recognized, and the duration of life may be rstimated with a fair degree of accuracy. I refer to such symptoms as breathlessness, associated with cyanosis and pulmonary congestion, and the pain of angina pectoris; such symptoms are associated with definite signs of heart failure. The disease is no longer in its early stages; our problem is an easy one, total disability is obvious, and prognosis is of less consequence. The prognostic task vecomes a more difficult one when we are required to foretell, in the patient with early heart disease, the number of years remaining before the final stage of total disability has been reached. When will the patient with mitral stenosis and no symptoms have symptoms due to cardiac fallure? With symptoms after effort when may we expect signs of venous engorgement? These questions cannot be answered uniess we understand the symptoms and the relation they bear to the signs. Until we know what symptoms arise from loss of cardiac reserve through myocardial disease, and can recognize the early symptoms of heart failur., and identify symptoms due to other causes, it will not be possible to prognose with any degree of certainty in early mitral stenosis.

We know from experience that the course of the disease is a progressive one, the disability an increasing one, and lieart failure the end of most patients with mitral stenosis. 'The duration of life may be shortened by repeated attacks of rheumatic fever, or other infections, or prolonged by the mode of living and proper care. A single attack of rheumatic fever many years back, with good health since, provided the heart is not enlarged, or only slightly increased in size, may be an indication that the disease is stationary. With the heart much enlarged the onset of heart failure in most cases is not far off.

1 Catton: "Observations on hypertrophy," Heart, vi, 217.

THE Board of Trade has received through the Norwegian Consul-General two silver cups awarded by the King of Norway to the master and the surgeon, Dr. A. Humphreys, of the steamship Haverford, of Liverpool, in recognition of their services to rescued members of the crew of the Norwegian steamship Augvald in the North Atlantic Ocean on July 4th, 1918.

\section{APPARENT SPONTANEOUS RUPTURE OF A} NORMAL SPLEEN.

BY

W. WOOD SHORTEN, F.R.C.S.ED., MAJOR R.A.F.M.S. Surgical Spegialist. Stationary Hogpital. B.E.F. FRANCE.

AfTer considering possible alternatives I have come to the conclusion that the following must be counted a case of spontaneous rupture of the normal spleen.

A private aged 43 years, whilst walking from his officon's billet to his own at 11.30 a.m. on December 20th, 1917, was seized with pain in the region of the umbilicus, so severe tha it caused him to fall to the ground. He vomited, and the pain subsided sufficiently to allow him to walk to his billet. He
endeavoured to carry on his duties, which were light, bnt, the pain getting worse, at 3.30 p.m. he reported sick, and was, the by his medical officer, who oame to the conclusion he had colio and gave him a dose of castor oil, which he immediately vomited. As the pain was getting steadily worse he was sent to hospital.

When he arrived, at 6.30 p.m., I found him very collapsed; the temperature was $96.8^{\circ} \mathrm{F}$., the pulse 130 and very feeble; the face was ashy grey. There were no external signs of injury. The abdomen was fiat and breathing entirely thoracic. He lay with his legs drawn up. The abdomen was tender and there was board-like rigidity of the abdominal muscles. The liver dullness was normal. Both flanks were dull whilst.lying on his back, shifting on turning over. Physical signs of bronchitis were present; the heart was normal. He vomited bile-stained were present; the heart was normal. He vomited bile-stained
fluid once after admission. The patient was so ill that he could fluid once after admission. The patient was so ill that he oould
not give a clear history of his previous life, but it was subsequently elicited that he had always been healthy except for chronic bronchitis during the winter. Eighteen moncept for viously he had been buried in the trenches and was admitted to hospital suffering from severe abdominal pain for which to was kept in bed for three weeks. Since pis dor which he hospital he had had no recurrence of that pain and had been well in every way except for the bronchitis. He had never been in a malarial oountry.

\section{Diagnosis.}

The diagnosis of rupture of an abdominal viscus was based on the marked abdominal tenderness and board-like rigidity of abdominal muscles and free fluid in abdominal cavity, but there were no localizing symptoms. The patient refused immediate laparotomy, but three hours later he consented. Morphine gr. $z_{\text {, }}$ atropine gr. ró given.

\section{Operation.}

At 10 p.m. the abdomen was opened in the middle line above the umbilicus; a large quantity of fluid and olotted blood escaped on opening the peritoneum. The abdomen was burriedly mopped ou '; the liver was found normal, but on passing the hand into the splenic region a large quantity of passing the hand into the splenic region a large quantity of A large rupture in the spleen was felt. When the splenio vessels were grasped the bleeding stopped. The wound was then extended transversely towards the costal margin, the left rectus being divided. The condition of the patient was too serious to allow an attempt at suture. The splenic vessels were isolated and ligatured with linen thread and the spleen removed. The wound was sutured with linen thread. The gall bladder was packed with stones, but was not touched. Subcutaneous saline was given continuously during the operation; warm ether saline was given continuously during the operation; warm ether was the anaesthetic administered. The pulse improved at the end of the operation, and he continued to make satisfactory
progress during the night. In the morning the temperatur was $98^{\circ}$ and the pulse 108 .

\section{Description of Spleen.}

The spleen was normal in size and weight; the tear, which extended from the convex surface to the hilum, divided the organ into two equal portions. There was no stripping of the capsule to suggest that at first there had been subcapsular haemorrhage later tearing through the capsule. It was clear that the tear in the spleen and capsule were present from the first, allowing of free intra-abdominal haemorrbage. Microscopical examination showed the spleen to be normal.

\section{Progress.}

The temperature ranged from about $100^{\circ}$ to $102^{\circ} \mathrm{F}$., but this was accounted for by the state of the chest. The pulse rate gradually dropped to 80 . The stitches were taken out on the tenth day. The wound healed by primary union. No glandular enlargements were observed; he made a rapid recovery from anaemia, and when he was evaeuated to England four weeks after the operation he was apparently in the best of health.

The question arises whether the injury he received eighteen months previously tore the spleen. If it did, there should have been some adhesions around the spleen or some sign of the old tear on the organ at the time of operation. I found no adhesions of any kind, and on examination of the spleen after the operation I found no evidence of an old tear; this was borne out later by
pathological examination. 
It may bo roggersed that at the atart of the atterck he had a gall. stone colic so severe that it carsed him to fall and in his fall strike some object which ruptared his spleen. I do not think this at all tikely, for he showed no external signs of injury either at first or later, and he would scarcely drop so helplessly ws to make his fall com. paratively heavy; he was absolutely confiderit that he fell on level ground without any stones or other objects likely to have caused the rapture. There was no jaundice, and when the abdomen was opened there was no evidence of stione in the ducts.

For my part, I do mot think either of these two reasons could be the cause of the rupture, and I must look upon it as a case of " spontaneous rupture of a normal spleen." I regret I was unable to bave a blood oonent made.

\section{THE RHLATION OF PFELFFER'S BACILLUS TO INFLUWNZA.}

\section{mr}

STANLEY WYARD, M.D., M.R.C.P.,

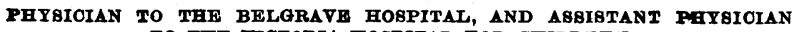
TO THE VICTORIA HOBPITAL FOR OHILDREN.

THE following report is based upon a number of cases -xamed during the 1918 epidemic. Attempts to obtain cultures from the circulating blood were made in three cases, and trom the beart's blood post mortem in two. Of the former, two were sterile and one yielded streptococci; of the latter, one was terile and one gave streptococci. In no anse was Pfeiffer's bacillas discovered, and of three swabs taken from the nasopharynx none showed this organism. Cultures were made from the sputum in seventy. three cases, the specimens in all cases being parralent or muco-purulent in character. The Beceillus infuensae was recovered seventeen times (24 per cent.).

The earliest cultures were made on agar smeared with fresh human blood, but the results with this medium were not equal to those with the media afterwards ased, and the percentage of positive results was smaller. The later media were Levinthal's and Flemming's. Both were prepared treshly for each plate (within twelve hours).

Iewinthal's was prepared by melttug some nutrient agar, cooling to $75^{\circ} \mathrm{C}$., and adafing 5 per cent. citrated human blood. The whole was then just brought to the boil, cooled $10^{\circ}$ to $15^{\circ} \mathrm{C}$. and raised a second time to ebrillition; it was fnatly passed through a sterile ganze and cotton-wool niter and poured immediately in plates.

Flemming 28 was prepared as follows: Stock flasks containing $160 \mathrm{c.cm}$. nutrient agar were prepared and kept ready for use. Human blood was obtained and added to ffve times its quantity of tap water and an equal quantity of $\mathrm{NHCl}$. The mix ture wa well stirred and preserved in a sterile stoppered bottle in the ice chrest for three to seven days. This was found necessary to ensure sterility. Tubes put up with blood newly treated were contaminated with $B$, subtilis in from 25 to 50 per cent. Immediately before ase $14 \mathrm{c.cm}$ of the rcidulated blood were taken and $2 \mathrm{ccm}$. of normal $\mathrm{NaOH}$ added nixed thoroughly and the reaction adjusted to just blue to litmen. The whole amount reaction adjusted to just blue to titmas. The whole

Both these media proved highly satisfactory but rapidly lost the power of giving good growths. The primary culture and first and second subcultures must be made on the freshly prepared medium. Subsequently the organism becomes acclimatized and will grow on older media.

Pfeiffer's bacillus grows on them as minute, round colourless colonies, which generally require thirty-six hours' incubation before they can be picked off for subcaltare. Here, as on other media, they show a marked tendency to congregate round colonies of staphylococci. An organism was accepted as a true $B$. influenzae if it was a minute Gram-negative cocco-bacillus with slightly tapering ends, non-motile, growing best on blood media, and staining only slowly with ordinary anihine dyes.

For further investigation three strains were chosen numbered 14, 16, and 43, after very numerous replatings to ensure absolute purity.

- I have been unable to discover any references in bacteriological Hterature to either of these media. In both cases the details of th preparation were commiaifioaited to me personally by a fellow worker. I belteve that the seowd has not yet been published, bnt sory cimilar method has been devised by Hundeshagen, Deut. med. Wook. 1918, 44, 1181, quoted by the Medieal Supplement to the Daily Kevie of the Foreign Pressi, vol. i, No. 12, December, 1918, p. 456.
Pathogensioity.-Nane of the strains produced any symaptoms when injected intraperitoneally into rats or intravenously into rablits.

Immunity.-A suspension of strain 14 was pat up against the serum of a rabbit by Dreyer's technique. No agglutination occurred. The same rabbit received on the following day, December 5th, 1918 :

At 10.55 a.m. an intravenous injection of one agar slope of strain 14 suspended in physiological saline to which had been added 0.5 per cent. phenol, the whole having been heated to $60^{\circ} \mathrm{C}$. for thirty minutes.

At 11.55 8.m. a second slope culture of the same strain similarly prepared was injected intravenously, and again at $12.55 \mathrm{pm}$, : third elope. The animal remained perfectly well.

On December 12th, 1918, two slopes of strain 14 were given into the ear vain. This time the orgenisms were living. Again no ill effects ensued.

On December 15th, 1918, a fow c.cm. of blood were drawn of and the serum put up againgt all three strains of the bacillus, with the following regults (in Dreyer's nomenclature):

\begin{tabular}{|c|c|c|c|c|c|c|}
\hline \multirow{2}{*}{\multicolumn{3}{|c|}{ Strain. }} & \multicolumn{4}{|c|}{ Dilution of Serum. } \\
\hline & & & \multirow{2}{*}{$\frac{125 .}{\mathbf{T}}$} & \multirow{2}{*}{$\frac{250 .}{T-}$} & \multirow[t]{2}{*}{625.} & \multirow[t]{2}{*}{1,250 . } \\
\hline 14 & $\ldots$ & $\ldots$ & & & & \\
\hline 16 & $\cdots$ & ... & $\mathbf{a}$ & $\mathbf{T}$ & $\mathbf{s}++$ & $8+$ \\
\hline 43 & $\cdots$ & $\ldots$ & $\mathbf{T}$ & $\mathbf{T}-$ & $\mathbf{s}+$ & $\mathbf{s}$ \\
\hline
\end{tabular}

On December 20th, 1918, the rabbit was bled to the amount of $20 \mathrm{c.cm}$.; the serum removed and used as a control for further experiments. It consistently gave a clear agglutination of all three etrains in dilution of 1 in 1,250 .

Having demonstrated the antigenic properties of these strains, the serums of patients suffering from influenza were put up against them with unvarying negative results.

\begin{tabular}{|c|c|c|c|}
\hline \multicolumn{2}{|c|}{ Bronchopneumonia Present. } & \multicolumn{2}{|c|}{ Bronchopneumonia Absent. } \\
\hline Week of Disease. & $\begin{array}{l}\text { No. of Serums } \\
\text { Examined. }\end{array}$ & Week of Disease. & $\begin{array}{l}\text { No. of Serums } \\
\text { Examined. }\end{array}$ \\
\hline 1 (1-7 days) & 3. & 1 (1-7 days) & 12 \\
\hline $2(8-14$ days $) \quad \ldots$ & 8 & $2(8-14$ days $)$ & 11 \\
\hline 3 (15-21 days) $\ldots$ & 4 & 3 (15-21 days) $\ldots$ & 10 \\
\hline 4 (22-28 days) ... & 5 & 4 (22-28 days) & 1 \\
\hline 5 (29-35 days) $\ldots$ & 3 & 5 (29-35 days) $\ldots$ & 2 \\
\hline Total ... ... & 23 & Total $\ldots$ & 36 \\
\hline
\end{tabular}

From this table it is seen that no agglutination of either of three typical strains of Pfeiffer's bacillus was obtained with serums removed from 59 cases of influenza, whether those cases were or were not complicated by bronchopneumonia, and whether they were in the, first, second, third, fourth, or fifth week of the disease.

When it was found that agglutination tests failed to reveal the presence of antibodies in the blood of influenza patients, attempts were made to discover them by means of complement fixation tests; but here a difficulty arose in the preparation of the antigen. At first a suspension of the bacilli in 0.85 per cent. saline was employed. The growth on-several agar slopes was washed off in saline and washed several times. Unfortunately great difficulty was experienced in ototaining the use of a centrifuge, so that the washing was not as thorough as oould be wished. Possibly more perfect washing would have altered the result. As it was, every suspension that it was possible to obtain was so strongly anticomplementary of itself that no complement fixation testis in the presence of a possible antibody could be carried out.

In order to overcome this, further cultures were washed off the medium with normal $\mathrm{NaOH}$, a little of the latter being used for much growth of the bacilli. The suspension was kept on ioe for a few days, and then nentralized exactly with normal HCl. Finally it was dilated with distilled water to give a $\mathrm{NaCl}$ content of 0.9 per cent., and further diluted with saline to give the requisite strength of antigen. This was determined empirically for each strain. Eight serums were put up against all three antigens, and in no case was the complement fixed. 